\title{
Towards a History of Infective Endocarditis
}

\author{
ALAIN CONTREPOIS*
}

Infective endocarditis is a serious heart disease which is sometimes very difficult to diagnose and treat despite the progress made over the last few decades. The complex nature of the pathophysiological mechanisms involved in this disease is reflected in the countless number of scientific studies still being done on it. ${ }^{1}$

At the end of the eighteenth century and during the first half of the nineteenth century, the anatomo-clinical method facilitated the gradual establishment of correlations between a lesion discerned during autopsy and symptoms observed in the live patient. It then became a question of bringing together what were, until then, separate individual observations. The very term "endocarditis", referring to an individual tissue and an inflammatory process, goes back to early-nineteenth-century clinicians such as Broussais and Bouillaud, before the germ theory and the birth of bacteriology.

However, it was very difficult for doctors of that period to define endocarditis in a simple, unequivocal manner. There was not always a clear relationship between the ideas which late historians have supposed fed each other; the arguments were confusing, tortuous, circular, and dead-end. In his discussion of syphilis, Ludwik Fleck correctly pointed out that disease is a constructed, ever-changing phenomenon which constantly integrates new information and concepts. ${ }^{2}$ Thus, the term "endocarditis" continued to be used for a disease which underwent endless development throughout the nineteenth century. There was also modification of the aetiological links between anatomical abnormalities, clinical symptoms and observations during autopsy. The pathology of the disease was regularly reformulated and its definition varied from period to period and from country to country. The germ theory and the use of the microscope changed the view and concept of the disease at the end of the century. But, even if an instrument suddenly enhances the power of the senses, the knowledge thus acquired needs to be interpreted by human beings. The fact of being able to "see" minute granulations hitherto invisible is not enough immediately to transform these granulations into an analytical tool. The perception of the disease as a relatively coherent whole with aetiological symptoms, led,

\footnotetext{
*Alain Contrepois, INSERM U158 (Université René Descartes, Paris V), Hôpital Necker-Enfants Malades, 75015 Paris, France.

I am indebted to Patrice Pinell for his guidance in this research and to Anne-Marie Moulin and Christiane Sinding for their helpful comments on earlier versions of this paper. The support of the Institut Beecham (Nanterre, France) for part of this work is gratefully acknowledged.

1 The experimental animal model for endocarditis continues to be one of the most studied
}

in the field of infectious pathology. In particular, it assists in the collection of important data on the distribution of antibiotics in the infected tissue (the inner membrane of the heart and, in particular, the heart valves), on the local activity of the antibiotics on the micro-organisms responsible for the infection as well as on bacterial adhesion to the endocardium.

${ }^{2}$ Ludwik Fleck, Genesis and development of $a$ scientific fact, eds T J Trenn and R K Metton, University Chicago Press, 1979, pp. 1-19. 
nevertheless, to laboratory experiments on diseases. ${ }^{3}$ At the beginning of the twentieth century, before the dawning of the first rays of therapeutic hope, a few clinicians tried to shed light on the somewhat confused knowledge of endocarditis and to surmount the formidable problem of describing and classifying this complex disease. ${ }^{4}$

Any attempt to "reconstruct" a history of this disease, therefore, will not be an easy task, for as Georges Canguilhem remarked, "Before joining up two tracks, you have to first be sure that they belong to the same path" 5 There is, for every researcher, at any given time, a particular area which he tries to explore and in which he attempts to build a set of relationships, not only through observation and techniques, but also in keeping with current practices, values and interpretations.

\section{Autopsies and Symptoms}

\section{Abnormalities}

At the end of the seventeenth century and during the eighteenth, a new medical outlook emerged as a result of anatomical observations made during autopsies. Some observers were struck by the unusual nature of anatomical anomalies of the inner membrane of the heart, and of the valves in particular. The term "anomaly" is being used deliberately here. Canguilhem, referring to Lalande's "vocabulaire philosophique", points out that the word is derived from the Greek word "anomalia" which means inequality or unevenness of a surface; "omalos" in Greek signifies that which is uniform, even or smooth. "Anomaly" then is derived from "an-omalos", that is, uneven, rough, irregular, much as one would speak about terrain. The "terrain" in this case, usually smooth, is the inner lining of the heart as well as the valves. On the other hand, according to I. Geoffroy Saint-Hilaire, abnormal is a descriptive concept and anomaly a normative one. As far as he is concerned, "in anatomy, the term abnormality should be used strictly to mean strange or unusual; to be abnormal is to be different from the vast majority of persons with whom one is compared."7 The two meanings of the term seem to apply here. A number of symptoms were described along with these anatomical anomalies, and it is interesting to note the marked similarity between work carried out in France, Italy and England.

According to Laënnec, one of the first descriptions of cardiac pathological alteration came from Lazare Rivière, professor of Medicine at the University of Montpellier. When in 1646 he was consulted by a patient who complained of palpitations, Rivière detected the following symptoms and signs: first, a faint and irregular pulse. A month later, the

\footnotetext{
${ }^{3}$ Andrew Cunningham and Perry Williams, The laboratory revolution in medicine, Cambridge University Press, 1992, pp. 1-13.

${ }^{4}$ Russell Maulitz and Diana Long (eds), Grand Rounds, one hundred years of internal medicine, Philadelphia, University of Pennsylvania Press, 1987, pp. 296-336.

5 Georges Canguilhem, Études d'histoire et de philosophie des sciences, 5th ed., Paris, J Vrin, 1983, p. 21.
}

${ }^{6}$ Georges Canguilhem, The normal and the pathological, transl. Carolyn R Fawcett, New York, Zone Books, 1989, pp. 131-2; original French title, Le Normal et le pathologique, Paris, PUF, 1979.

${ }^{7}$ Isidore Geoffroy Saint-Hilaire, Histoire générale et particulière des anomalies de l'organisation chez l'homme et les animaux, 3 vols, Paris, Baillière, 1832-7, vol. 1, pp. 30-49. 


\section{Towards a History of Infective Endocarditis}

patient was suffering from respiratory problems and swollen legs; the patient's condition progressively worsened; his difficulty in breathing increased and there was no pulse at the wrist; "when I placed my hand over his heart", Rivière detected a faint, rapid and irregular palpitation. After the patient died, Rivière performed an autopsy and in the left ventricle he found some "small round outgrowths resembling the lungs in texture, the largest of which was about the size of a hazelnut, which blocked the aortic valve". This description seems to indicate that Rivière had some knowledge of the internal structure of the heart and that what he observed in this case struck him as peculiar. ${ }^{8}$

In 1708, the Italian Giovanni Maria Lancisi also wrote of the unusual phenomenon of lesions inside the heart at the entrance to the aorta observed during autopsy: "I saw some rough structures on the valves as well as small nodules of flesh". For Lancisi, there was no doubt that these hard bodies were projections of the fibres and valvular tissues and were not simply stuck to them. ${ }^{9}$ In 1715 , Raymond Vieussens, professor at Montpellier, identified certain abnormalities in the aortic mitral valves, ${ }^{10}$ and in 1749 , Jean-Baptiste Sénac also described valvular lesions. ${ }^{11}$

But, at what stage does an observed abnormality become a disease? Giovanni Battista Morgagni (1682-1771) identified diseases according to the local distribution of their symptoms as well as their point of origin. A disease occurs at the organic level. Morgagni believed that a patho-anatomical examination must constantly refer to the anatomy of the normal person, obviously, but, at the same time, to clinical experiments as well. In the $D e$ sedibus, he mentioned a post-mortem observation of a large number of outgrowths on the aortic valves and, in addition to this cardiac abnormality, "adipose ramifications" on the spleen. It was pointed out that the patient had virulent gonorrhoea but no clear relation was established with symptoms and anatomical lesions. ${ }^{12}$ Sandifort illustrated his observation of these intracardiac abnormalities with the help of extremely eloquent diagrams. ${ }^{13}$

Meanwhile, in London, Matthew Baillie (1761-1823) described deformations of the heart and the aorta. He recognized "rheumatic carditis" and the relationship between rheumatism and certain heart diseases, confirming this in the second edition of his Morbid anatomy which appeared in 1797. However, although he discussed "ossification" and thickening of the heart valves in detail, he believed that inflammation was a rare occurrence: "I have also seen the valvular apparatus between the auricle and the ventricle, in a state of inflammation, and covered with a layer of coagulable lymph. This I believe to be very uncommon."14

\footnotetext{
${ }^{8}$ René T Laënnec, De l'auscultation médiate ou Traité du diagnostic des maladies des poumons et du coeur, 2 vols, Paris, Brosson et Chaudé, 1819, vol. 2, p. 334. The case Laënnec mentioned was described in Rivière's Observationes medicae, cited in Jean Astruc, Mémoire pour servir à l'histoire de la Faculté de Médecine de Montpellier, Paris, Cavelier, 1767, p. 259.

${ }^{9}$ Giovanni M Lancisi, De subitaneis mortibus, Venice, Poleti, 1708, p. 225.

${ }^{10}$ Raymond Vieussens, Traité nouveau de la structure du coeur et des causes du mouvement naturel du coeur, Toulouse, Guillmette, 1715, pp. $120-4$.
}

\footnotetext{
11 Jean-Baptiste Sénac, Traité de la structure du coeur, de son action et de ses maladies, 2 vols, Paris, J Vincent, 1749, vol. 2, pp. 286-7.

12 Giovanni B Morgagni, The seats and causes of diseases, London, Millar and Cadell, 1769, vol. 1, p. 730; original Latin title, De sedibus et causis morborum per anatomen indagatis, libri quinque, Venice, Remondini, 1761.

${ }^{13}$ Eduard Sandifort, Observationes anatomicopathologicae, Leyden, Eyk and Vygh, 1784.

${ }^{14}$ Matthew Baillie, The morbid anatomy of some of the most important parts of the human body, 2nd ed., London, J Johnson \& G Nicol, 1797, pp. 32-4, on p. 34 .
} 


\section{Alain Contrepois}

\section{The Botany of the Heart}

In 1799, Xavier Bichat (1771-1802) devoted his Treatise on the membranes to a detailed study of general pathological forms which added a new dimension to Morgagni's anatomical distribution of symptoms, thus passing from localization to tissue organization. ${ }^{15}$ It then became evident that there were large families of diseases with the same major symptoms, which developed in the same way. Bichat was also responsible for elucidating the notion of tissue inflammation. All serious membrane inflammation was recognized by the characteristic thickening, loss of transparency, whitish colour, granular alteration and adhesion of these membranes to adjacent tissue. ${ }^{16}$ But inflammation which appears under the same form in all the seriously affected membranes does not attack them all with the same ease nor does it develop at the same speed: "the following are affected by descending order of susceptibility: the pleura, the peritoneum, the pericardium, the vaginal membrane and the arachnoid". The heart, like other organs, is made up of different types of tissue. Bichat pointed out that a disease could be localized in only one membrane and one tissue of a hollow organ independently of the rest of the organ. However, although Bichat referred to the pericardium, he made no mention of the internal lining of the heart and possible abnormalities. Nevertheless, he described the inner lining of vessels as

forming a continuous surface on the inside of vessels divided into two parts: the first part consists of the veins, the right auricle, the right ventricle and the pulmonary artery; the second consists of the pulmonary veins, the left auricle and left ventricle, the aorta and other arteries. ${ }^{17}$

These two internal surfaces join at the point where the arteries end and the veins begin. The degree of sensitivity of each type of membrane depends on the type of blood with which it comes into contact.

While Bichat was carrying out his studies, in 1806, Jean Nicolas Corvisart (1755-1821) was writing his Essay on organic diseases and lesions of the heart and great vessels. Corvisart was probably the first person to use a botanic term - "vegetations"- to refer to the outgrowths observed in the heart and this botanic reference was also extended to the similarity between these "vegetations" and venereal "cauliflower":

Under the denomination of vegetations, I do not mean to speak of the eminences, or osseous asperities, but of actual excrescences or soft vegetations, whose nature would be entirely unknown, did not a perfect resemblance to venereal excrescences, and certain approximations made from a number of observations, lead us to think that they might be syphilitic. Why then do we hesitate to believe that the venereal virus from its protean nature cannot attack organs, which seem, by their situation, to be secure from such attacks?

Thus, according to Corvisart, and as Lancisi seemed to have already imagined in 1707, budding is the best explanation for the growth of these vegetations.

There had been no real attempt to give a clinical explanation for these cardiac abnormalities until Corvisart came up with the idea that the syphilitic virus could be the

\footnotetext{
15 Xavier Bichat, $A$ treatise on the membranes in general, transl. John G Coffin, Boston, Cummings and Hilliard, 1813; Traité des membranes, Paris, Richard, Caille et Ravier, 1799/1800.

16 Xavier Bichat, Anatomie générale, Paris, Brosson, Gabon, 1801, vol. 1, Foreword, p. xcvii.
}

\footnotetext{
${ }^{17}$ Xavier Bichat, Anatomie pathologique, Paris, Baillière, 1825, pp. 3-39, on p. 39; Treatise on the membranes, op. cit., note 15 above, p. 138.
} 


\section{Towards a History of Infective Endocarditis}

cause of these unusual anatomical manifestations. Furthermore, he wondered if it would not be possible to use anti-venereal treatment in cases where a diagnosis could be established. In one of his many clinical observations, after noting the connection between the patient's exposure to different weather conditions and swelling of the extremities, he made no explicit link between rheumatic pain, fever and cardiac lesions. He mentioned the outer membrane of the heart-the pericardium-and pointed out that the presence of vegetations could cause narrowing of the orifices and consequently block circulation:

Clinical observation No. 37 of N Corvisart (1806):

A quarry-man, aged thirty-nine years, of a robust constitution, but very intemperate, exposed, by occupation, to the vicissitudes of heat and cold, suffered, at the age of twenty years, rheumatic pains, which impaired his health but for a short time.

About the $22 \mathrm{~d}$ of November, 1800 , he was attacked with peripneumony, which was, to appearance, well cured; after his convalescence, he was, however, harrassed by an obstinate cough and pain in the right hypochondrium; to these symptoms were soon after joined, hoarseness, vomitings produced by the violence of the cough, and paroxysms of fever in the evening; in short, swelling of the extremities. Having left the Hospital Cochin, where he was treated for the peripneumony, he entered the HotelDieu, but he departed immediately for the purpose of entering the Hospital of la Charité, which he soon quitted, and into which he was again received, June 9th, 1800. All the animal functions were benumbed; he scarcely answered the questions which were asked him; the features were altered, the countenance grown old, pale, yellowish and bloated; ... The hand laid over the region of the heart felt no irregularity in its strokes, which might rationally be attributed to the considerable oedema of the parietes of the thorax.... The pulse was frequent, small and irregular.

The very dull sound of the region of the heart, the character of the pulse, dyspnoea, color of the lips, expression of the countenance, ... induced me to suspect a lesion of this organ. The prognosis was that the patient must die soon. Medicine gave no relief. ... [on] 12 th of June, . . he died when asking for drink, without a symptom of distress.

On dissection ... [t] $]$ he pericardium contained a little water. The heart was somewhat larger than natural; . . . The large portion of the mitral valve, which lies before the orifice of the aorta, held no longer by the tendinous threads to the columnae carneae in which these filaments terminated. At its edge, become loose, many species of very irregular and long vegetations were appended, imitating certain venereal excrescences ... ${ }^{18}$

Corvisart's ability to make a precise diagnosis on a correlation between the clinical aspect and pathological anatomy was something which, according to $\mathrm{P}$ Rayer, ${ }^{19}$ often surprised his listeners. He was "a pioneer of pathological anatomy; every case dying on his wards was autopsied". ${ }^{20}$ Corvisart regularly placed his hand over his patient's chest during clinical examinations (we have seen that Lazare Rivière was already doing this in 1646). This practice provided him with an important semiological datum - the heart "murmur". ${ }^{21}$ After palpation, he also performed percussion conceived forty years earlier by Auenbrugger.

\footnotetext{
18 Jean N Corvisart, An essay on the organic diseases and lesions of the heart and great vessels, transl. Jacob Gates, Boston, Bradford \& Read, 1812, reprinted New York, Hafner, 1962, pp. 175-8; French title, Essai sur les maladies et les lésions organiques du coeur et des gros vaisseaux, Paris, Migneret, 1806.

${ }_{19}$ Pierre Rayer, Sommaire d'une histoire abrégée de l'anatomie pathologique, Paris, 1818, p. 131.
}

\footnotetext{
${ }^{20}$ Erwin H Ackerknecht, Medicine at the Paris Hospital, 1794-1845, Baltimore, Johns Hopkins Press, 1967, pp. 84; La médecine hospitalière à Paris, Payot, 1986, pp. 109-12.

${ }^{21}$ Corvisart, op. cit., note 18 , above, pp. 182-5: "By observing the disorder of the circulation, the practitioner may find, in the living man, I should presume, certain signs of this species of affection. ... Beside the general signs of the diseases of the heart,
} 


\section{Alain Contrepois}

The Englishman Allan Burns (1781-1813) had a different view of how vegetations were formed. He was interested in the effect of the changed structure of the heart valves and large arteries and in his description of an autopsy, noted that:

The left auricle contained a concretion larger than a pigeon's egg; this substance was of an irregular form, it appeared as if it had been composed of several portions forcibly pressed together; it was of firm consistence, but somewhat friable, and of granular structure; it . . . adhered firmly to the side of the cavity ... 22

The term "concretion" conjures up the image of an agglomeration of granular, friable particles which adhere to the wall and not an outgrowth or budding of the tissue. Burns mentioned a "frothy lymph" on the inside of the auricle. He reported three cases of mitral stenosis and also described "a very unusual fluttering in the breast." Is this the "murmur" which Corvisart spoke of? Quite likely.

Friedrich Kreysig of Germany wrote in 1815 about "polypous carditis" and the effect of rheumatism on the heart. According to him, the polypous concretions of the heart cavity were products and therefore proofs of inflammation. ${ }^{23}$ In Kreysig's opinion, rheumatic metastasis was not so much an alteration of the inner lining of the heart as the presence of "blood clots" in the heart cavity. According to this theory of concretions, coagulation occurs before adherence to the cardiac membrane.

\section{Ear to Heart}

In 1816, Théophile Laënnec (1781-1826), a pupil of Corvisart's, invented his "cylindrical" stethoscope, which greatly improved auscultation, especially cardiac auscultation. ${ }^{24}$ It took several years for doctors to become accustomed to putting their ear to their patient's chest to listen to what was happening and draw conclusions. Others before had looked, then others such as Rivière and Corvisart had touched, and now Laënnec was listening. This was even harder. In fact, it seems that it was doctors' sense of decency and the moral standards of the day which were partly responsible for the invention of the stethoscope. It avoided the doctor placing his ear directly against the patient's chest.

Laënnec published the first edition of his De l'auscultation médiate in $1819 .{ }^{25} \mathrm{He}$ disagreed with his teacher on the origin of valvular vegetations, writing that:

\footnotetext{
which are ever found in this case as in the first, because an aneurismal complication generally obtains, some particular signs manifest the affections in question. Of the preceding number of symptoms is a peculiar rushing like water, difficult to be described, sensible to the hand applied over the precordial region, a rushing which proceeds, apparently, from the embarrassment which the blood undergoes in passing through an opening which is no longer proportioned to the quantity of fluid which it ought to discharge."

22 Allan Burns, Observations on some of the most frequent and important diseases of the heart, Edinburgh, Bryce, 1809, pp. 163-91, on p. 174.
}

\author{
${ }^{23}$ Friedrich L Kreysig, Die Krankheiten des \\ Herzens, 3 vols, Berlin, In der Maurerschen \\ Buchhandlung, 1814-17. See James B Herrick, $A$ \\ short history of cardiology, Springfield, ill., Charles \\ C Thomas, 1942, pp. 81-3. \\ 24 Jacalyn M Duffin, 'The cardiology of R. T. H. \\ Laennec', Med. Hist., 1989, 33: 42-71. \\ ${ }^{25}$ Laënnec, op. cit., note 8 above; Ruth J Mann \\ and Frank D Mann, 'Laennec as a critical \\ pathologist', J. Hist. Med., 1981, 36: 446-54.
}




\section{Towards a History of Infective Endocarditis}

The venereal origin of these excrescences, entertained by $\mathbf{M}$. Corvisart, appears to me very improbable, when we consider their rarity and the frequency of venereal complaints, and when we meet with them, as we do, in individuals who, in all probability, never had this disease. ${ }^{26}$

In spite of his careful choice of words, Laënnec's last argument, which contradicted the venereal aetiology of the vegetations, was convincing. James Hope would later confirm Laënnec's observations in $1832 .^{27}$

There was therefore no real construction of a clinical entity up to 1830 . Besides, the argument that the valvular vegetations had syphilitic origins was refuted. However, some of the lesions' effects on the "heart's mechanics" were noted, especially certain signs or "noises". A number of symptoms were described fairly accurately, although they were not necessarily related to the valvular vegetations: palpitations, respiratory difficulty, swollen legs, rheumatic pain, coughing, fever, fatigue and dyspnoea. The observation of "vegetations", "concretions" or "outgrowths" on the heart valves or in the heart cavity during autopsy did not lead to the identification of a specific disease. These various abnormalities, alterations or lesions can be deceiving in that what was observed was a final picture, a post-mortem. It was therefore difficult at times to know what was there at the outset, what followed and even what could have appeared after death in a disease that became more and more complicated over time.

Improved clinical observation techniques, information gained through percussion and auscultation gradually established symptoms which corresponded to lesions observed during autopsy. There then was a search for a means of detecting these lesions in the live patient. In Paris especially, a veritable "research spirit" turned the hospital into a sort of laboratory, in addition to being a teaching institution. ${ }^{28}$ The hospital then became the autopsy centre and between 1800 and 1850 Paris became something of a medical lighthouse. It is within this context that J B Bouillaud, one of the great contributors to hospital medicine at the time, established a specific nosography.

\section{Bouillaud's Endocarditis}

Jean-Baptiste Bouillaud (1796-1881) entitled his thesis written in 1823 Essai sur le diagnostic des anéurismes de l'aorte with special emphasis on the use of auscultation. The following year, he wrote a Mémoire sur le rétrécissement de l'un des orifices du coeur et sur les effets de cette lésion. This work was, in fact, the prelude to his future research on heart disease. In 1824, Bertin and Bouillaud jointly published a Traité des maladies du coeur et des gros vaisseaux. In their introduction, they spoke of "the outer membrane of the heart, the pericardium, and the inner membrane of the heart which joins the inner

\footnotetext{
${ }^{26}$ René T Laënnec, $A$ treatise on disease of the chest, London, T \& G Underwood, 1821, p. 245.

27 James Hope, A treatise on the diseases of the heart and great vessels, London, W Kidd, 1832, p. 506.

${ }^{28}$ Some of the classic works on this subject are: Erwin Ackerknecht, op. cit., note 20 above; Michel Foucault, The birth of the clinic, transl. A M
}

Sheridan, London, Tavistock, 1973; French title, Naissance de la clinique, Paris, PUF, 1963; Toby Gelfand, Professionalizing modern medicine: Paris surgeons and medical science and institutions in the 18th century, Westport, Conn., Greenwood Press, 1980; Russell Maulitz, Morbid appearances: the anatomy of pathology in the early nineteenth century, Cambridge University Press, 1987. 


\section{Alain Contrepois}

lining of the vessels . . . It forms the heart valves by folding over on itself and around a fibrous tissue." 29 The formulation of the sentence seemed to be leading to a precise term for the inner membrane but this was not the case.

\section{Naming the Parts}

"So little is known about the disease whose history is being traced here that it does not even have a specific name. My proposal in this respect seems to conform to the current general principles of nomenclature." So said Bouillaud in the first edition of his Traité clinique des maladies du coeur, published in $1835 .{ }^{30} \mathrm{He}$ took up from where Bichat left off, but went further; after identifying the outer membrane, the pericardium, he gave a name to the inner membrane: "endocardium". The diseases which affect this tissue, he said, occur more frequently than is believed, often going undetected at the acute stage before going on to attain chronic proportions:

I am not exaggerating when I say that the affections of the endocardium, or the inner membrane of the heart, are the most usual starting point, the most frequent generator of these multiple organic lesions, whether in the valves, the walls or the cavity of the heart. ${ }^{31}$

We are, therefore, at the very centre, at the heart of the heart, so to speak, at the point of origin or genesis of the affection of this central, vital organ. After describing the membrane, Bouillaud went on to add:

Normally the surface of the endocardium is extremely smooth. However, as a result of certain morbid diseases, this membrane can become uneven, rough and bumpy, so to speak. This lack of smoothness necessarily increases friction against the blood column which spans the heart cavity ... It is not known if, like the pericardium, the endocardium secretes a serous liquid which lubricates the inner surface. ${ }^{32}$

These two excerpts are important for understanding how Bouillaud saw the chronology of events. Certain morbid diseases can bring about a slight alteration of the endocardium, itself in turn automatically causing friction of the blood column in this region of the heart. Is this friction the cause of inflammation or is it a contributing factor? This local inflammation of the endocardium could be the direct cause of organic lesions in the valves and other structures of the heart.

Bouillaud extended Broussais' ideas on the "seat" of infection, irritation and "local inflammation". As far as Broussais was concerned, there was, in fact, only one cause of disease: irritation leading to local inflammation resulting in other lesions, but fever was only a symptom of irritation. There was no "fever" as an illness in itself. Broussais claimed that initial inflammation was generally gastric and intestinal. ${ }^{33}$ Bouillaud

\footnotetext{
${ }^{29}$ R J Bertin, Jean-Baptiste Bouillaud, Traité des maladies du coeur et des gros vaisseaux, Paris, Baillière, 1824, pp. xxiv, 169.

30 Jean-Baptiste Bouillaud, Traité clinique des maladies du coeur, 2 vols, Paris, Baillière, 1835, vol. 2, p. 1.

31 Ibid., vol. 1, p. 21: "Somewhat neglected by anatomists, the study of this membrane is of utmost
}

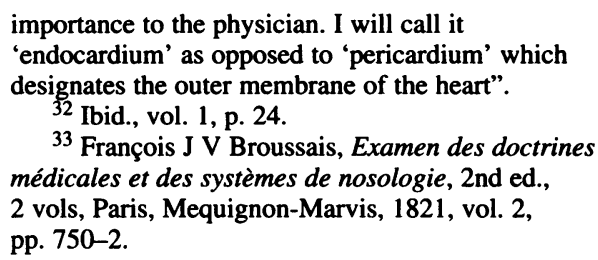

${ }^{33}$ François J V Broussais, Examen des doctrines médicales et des systèmes de nosologie, 2nd ed., 2 vols, Paris, Mequignon-Marvis, 1821, vol. 2, pp. 750-2. 


\section{Towards a History of Infective Endocarditis}

disagreed with his mentor on this point because he believed that a specific process of irritation occurred in the endocardium, on the heart valves in particular. He pointed out (p. 271) that even the most serious of several diseases attacking the centre of the circulatory system were subject to "the same influences" as those affecting other organs. The heart had found a new source of morbid diseases and this particularly in "febrile diseases". Which febrile diseases? Bouillaud was not very explicit. He claimed that valvular vegetations could be due to various "viruses", especially the syphilitic virus, but according to him, the existence of this virus "has been questioned by a number of modern observers". ${ }^{34}$ Furthermore, inflammation of the inner and outer membranes of the heart either accompanied or followed inflammation of the pleura and the lungs or the serofibrinous tissue of the joints (acute rheumatoid arthritis). ${ }^{35}$ Bouillaud argued that this affection was one of the causes of inflammation of the endocardium. He also highlighted the following signs: high skin temperature with diaphoresis at certain times of the day, shivering accompanying the fever and a bellows murmur.

\section{Constructing the Natural History of the Disease}

The systematic performance of autopsies allowed Bouillaud to measure the frequency of endocarditis and to identify its different stages: normal heart, redness and thickening, valvular vegetations, valvular damage. One of these stages consisted of his inflammation theory, although he did not admit it: "We would like our readers to know that we were not guided by any preconceived theory in what we have to say about inflammation of the endocardium, but rather, the theory followed the facts". 36

However, according to Bouillaud, if inflammation made its presence felt in this way only, medicine would be a blind science:

The doctor arrives at a diagnosis of the illness by studying the causes which have had an impact on the patient, by analysing the physical signs and functional lesions and by observing the development of the disease and its effect on the body. The pathological anatomy only complements, so to speak, what we already know. ${ }^{37}$

When he spoke of "the effect [of the affection] on the body", he seemed to be referring to reactions and symptoms apart from local cardiac lesions.

According to Bouillaud, the first phase of endocarditis consisted of blood congestion, softening of the membrane and suppuration but, he pointed out, the last was hard to prove: "Blood flows so rapidly and with such force through the heart's cavities that the substance which is gradually secreted by the inflamed endocardium must be constantly swept away by this flow of blood" ${ }^{38}$ During the second phase, the secreted substances are formed into vegetations or granulations which have a particular preference for the valves, although they are also found on the inner surface of the heart's cavities. These greyish-white

\footnotetext{
34 Bouillaud, op. cit., note 30 above, vol. 1, pp. $271-6$.

35 Another major contribution which Bouillaud made to cardiology was the formulation of a law establishing a correlation between acute rheumatoid arthritis and endocarditis, specifically discussed in his Traité clinique du rhumatisme articulaire, Paris,
}

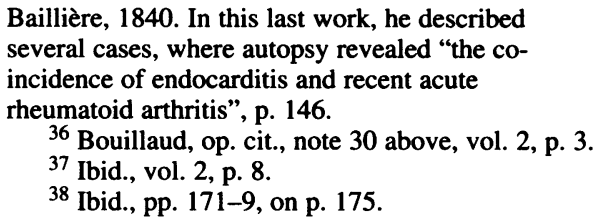




\section{Alain Contrepois}

"fibrinous vegetations" are easily detached. They can be small or large, they can come singly or in groups. Grouping of vegetations results in blockage of the openings at which the valves are located. In the third phase, the valves undergo cartilaginous induration and the heart's orifices are blocked to a much greater extent and may even be gradually destroyed. Of the four "general" symptoms pathologists have identified with inflammation, three are not immediately evident upon examination of the endocardium; namely, heat, redness and swelling. The fourth symptom, pain, is absent in most cases:

This symptom is often replaced by faintness and a feeling of suffocation in the precordium ... Much attention must be paid to the physical signs detected upon examination, palpation, percussion and auscultation. The bellows murmur, which sometimes masks the normal sounds of the heart, can be detected through auscultation ... This puffing, grating or sawing sound is sometimes short and spasmodic or long, prolonged and "drawn out", so to speak. A fairly high fever usually accompanies acute endocarditis. ${ }^{39}$

Bouillaud did not give any details on patients' temperatures. But we know that he noted the increase or decrease of "calorification" or heat production. Admittedly, the thermometer was not in frequent use at the time, but Bouillaud was among the first to recognize its practical value. He insisted that rest of the diseased organ, which is part of the treatment of acute and chronic diseases, was not applicable in the case of the heart. This idea would influence the treatment of these affections: extraction of large quantities of blood, to allow the heart to rest by reducing its circulatory function.

Clinical observation No. 13 of J B Bouillaud (1835):

A young girl, 18 years old, of delicate and scrofulous constitution, was admitted to the Clinic on December 22, 1832. She had been coughing excessively for 2 weeks, was expectorating a lot of mucous substance and complained of feelings of suffocation and general discomfort . . . Large bubbles of mucous rale were detected on both sides of the chest. When the lungs were auscultated from her back we were surprised to hear a distinct, extremely short puffing systolic murmur during ventricular contraction ...

Diagnosis: general bronchitis with blockage of the lungs; thickening starting with the valves of the heart with slight blockage of one orifice. Our observations during the earlier part of the disease and the absence of any indication of organic heart disease before the current affection left us in doubt as to the lesion which really caused the bellows murmur ...

Prescription: Blood-letting in two bleeding bowls, herbal tea, starvation diet. The following day we recommended that two scarified cupping glasses be placed at the back of the chest. There was some improvement but suddenly, on December 31, the suffocation became so great that the patient died during the day. An autopsy was performed 18 hours after death and the following observations were made: ... The aortic valves were red but not thickened. The mitral valve was thicker and its free end completely covered with multiple, convergent vegetations resembling leeks or venereal cauliflower; they were fibrinous, friable and easily crushed by the blade of the scalpel . . The condition of the valve obviously impeded its movement and thus prevented total blockage of the orifice at which it is located. ${ }^{40}$

In 1835, Bouillaud was convinced that whether occurring in isolation or along with other "plegmasias" (inflammations), the following signs would henceforth define a clinical entity: progressive local lesion (valvular vegetations following inflammation),

${ }^{39}$ Ibid., pp. 204-16, on pp. 204-6.

${ }^{40}$ Ibid., vol. 1, pp. 379-84. 


\section{Towards a History of Infective Endocarditis}

certain clinical signs, in particular the "bellows murmur" detected during auscultation, and frequent fever. But, according to him, endocarditis developed in two ways: either under the influence of immediate, direct causes ("primitive" or "idiopathic" endocarditis) or it occurred after, or concomitant with, another "phlegmasia" ("consecutive" or "sympathetic" endocarditis) such as pleuropneumonia, phlebitis or acute rheumatoid arthritis. He defined acute rheumatoid arthritis as an illness characterized by fever, pain in the joints, excessive sweating and other manifestations, especially in relation to the heart. He claimed that there was no specific determining cause but that it occurred "during atmospheric changes especially after prolonged exposure to relatively dry cold, or above all humid cold where a significant increase in body heat had led to perspiration". ${ }^{41}$

However, by 1841, in the second edition of his Traité clinique des maladies du coeur, Bouillaud had refined his ideas and divided endocarditis into two broad clinical categories. ${ }^{42}$ The first was a purely inflammatory affection which either developed independently, and was quite infrequent, or became evident during acute rheumatoid arthritis, pleurisy or pleuropneumonia. This was what Bouillaud referred to as "simple" endocarditis. The second category included the so-called "typhoid" diseases (putrid and septic). At the time, the generic term "typhus" or "typhoid fever" covered several febrile syndromes usually accompanied by stupor and delirium (these last two terms persisted long after the differentiation was made between typhoid and typhus; the term "tuphos" was kept). In this category, inflammation was the essential factor but it was greatly modified by the typhoid element. Bouillaud called it "typhic endocarditis" but was careful to point out that by this he meant endocarditis modified by a coexistent typhoid state and not endocarditis that gave rise to typhoid-related factors. He, therefore, established no direct link between the local cardiac lesion and certain general factors which were unrelated to purely circulatory problems. He spoke about two concomitant affections. The first was "septic", provoking the development of the second, which was localized in the endocardium and was "inflammatory".

This very complex issue concerning a local disease which could become generalized and a generalized disease which could become localized was to be long debated in the discussion on endocarditis. The nature and cause of valvular vegetations as well as other factors outside the heart were to fuel another lively debate.

\section{III}

\section{From Local to General Disease}

\section{Embolisms}

The Englishman William Senhouse Kirkes described certain phenomena attributed to the consequences of the release of fragments of cardiac vegetations into the bloodstream. ${ }^{43}$ According to him, the "fibrinous concretions" or "outgrowths" were broken

\footnotetext{
41 Ibid., vol. 2, p. 231.

42 Jean-Baptiste Bouillaud, Traité clinique des maladies du coeur, 2nd ed., 2 vols, Paris, Baillière, 1841, vol. 2, pp. 371-2.

${ }^{43}$ William Senhouse Kirkes, 'On some of the
} 


\section{Alain Contrepois}

down in the diseased valve. This could cause pieces of concretion of varying size to enter the blood-stream and block a vessel, depending on the size of the foreign body. Symptoms would then appear similar to those observed in typhus, phlebitis and other diseases where "the blood undergoes profound changes". He also described cases of patients with a systolic "murmur", fever, sometimes sweating and spots on the skin ("spots of a pinkish colour"), and who had succumbed to softening of the brain and hemiplegia, and other forms of paralysis or phlebitis. In some cases, the attack was preceded by acute rheumatoid arthritis a few weeks before. During autopsy, several valvular vegetations were observed and endocarditis was diagnosed. A fibrinous coagulum was sometimes found in a cerebral artery, in the kidneys or in the spleen. ${ }^{44}$

The local lesion, in this case the vegetations on the endocardium, was therefore, according to Kirkes, the point of departure for general or local lesions outside the heart which were unrelated to circulatory insufficiency. This idea is totally different from those expressed by Bouillaud, who had never imagined such a possibility. The cause of the initial lesion on the endocardium, which was a point of major concern for Bouillaud, was, however, not addressed by Kirkes.

Other researchers later subscribed to Kirkes' view of the disease but the frame of reference for explaining the appearance of the vegetations was not always clear. Rudolf Virchow supported the inflammatory theory but his approach was less "clinical" and more "physiological" than Bouillaud's. ${ }^{45} \mathrm{He}$ was, in fact, greatly influenced by the ideas which he developed in a study, entitled Die Cellularpathologie, on the microscopic examination of the fibrinous substance of the vegetations and infarctions. In chapter 10, headed 'Metastatical dyscrasiae' in the English translation, he pointed out that "thromboses" which travelled through the veins were also present in the heart where they appeared as "cysts" or as albuminous tumours. ${ }^{46}$ Parts of these thrombi would become detached, be transported in the blood-stream and embedded in vessels located far away from the heart. This would give rise to the morbid phenomenon usually referred to by Virchow as "embolism".

This was confirmed in Germany and France, notably in 1861 by Jean-Martin Charcot (1825-1893) and Alfred Vulpian (1826-1887). ${ }^{47}$ In their joint study they referred to Bouillaud and cited the studies carried out by Virchow, Rokitansky and Kirkes. These references are significant because they show that after Bouillaud, in-depth research on this subject was conducted less frequently in France than in Germany or England. Charcot and

\footnotetext{
44 Ibid., p. 324. He wrote: "1st, the general fact that fibrinous concretions on the valves or the interior of the heart admit of being readily detached during life, and mingled with the circulating blood: 2dly, that if detached and transmitted in large masses, they may suddenly block up a large artery, and so cut off the supply of blood to an important part; if in smaller masses, they may be arrested in vessels of much less size, and give rise to various morbid appearances in internal organs; while, under other circumstances, the particles mingled with the blood may be extremely minute, possibly the debris of softened fibrine, yet in sufficient quantity and with sufficient power to produce a poisoned state of the
}

circulating fluid, as manifested in the production of typhoid or phlebitic symptoms: 3 dly, that the effects produced and the organs affected will be in great measure determined by the side of the heart from which the fibrinous masses have been detached ...".

${ }^{45}$ Ralph Major, 'Notes on the history of endocarditis', Bull. Hist. Med., 1945, 17: 351-9.

${ }^{46}$ Rudolf L K Virchow, Die Cellularpathologie, Berlin, A Hirschwald, 1858; appeared in English as Cellular pathology, London, J Churchill, 1860.

47 Jean-Martin Charcot and Alfred Vulpian, 'Note sur l'endocardite ulcéreuse aiguë à forme typhoïde', C. R. Séanc. Mém. Soc. Biol., 1861, 3rd series, vol. 3, pp. 205-21. 


\section{Towards a History of Infective Endocarditis}

Vulpian indicated the symptoms which accompanied the typhic forms of endocarditis: high temperature, shivering, palpable spleen, sweating and sometimes small red spots on various parts of the body. They said that these symptoms were due to the "intoxication" induced by a "morbid poison" present in the blood and constantly produced in the abnormal endocardium. The typhic aspect was therefore secondary, appearing several days after the affection of the endocardium and this seemed to be the only explanation for the secondary development. Their autopsy report of a case of acute endocarditis indicates that microscopic examination of the valvular vegetations was done, that these were made up of fibrillar fibrin and that there were very few leucocytes but numerous "small granulations" (on which the authors made no comment). In this study, Charcot and Vulpian combined the ideas of Bouillaud with those of Kirkes and Virchow. Bouillaud believed that the typhic aspect succeeded the inflammatory alteration of the endocardium and Kirkes and Virchow wrote about the embolisms outside the heart created by fibrinous particles of valvular vegetations. However, some clinicians disagreed as to the local cause of the general symptoms observed in people with endocarditis. ${ }^{48}$ They believed that the lesion on the endocardium could not, by itself, produce all the various symptoms and that the specific aspects of the disease were due to the fact that it affected weak and cachectic people. The role of the "terrain", therefore, needed to be examined even before trying to explain the presence of these mysterious microscopic granulations. Was the local lesion then the point of departure for the general symptoms or was the disease first general and then localized on the endocardium?

From England, Samuel Wilks entered the debate in 1870 and proposed scarlet fever (a general disease) as a possible cause of the local valvular lesions on the endocardium. ${ }^{49} \mathrm{He}$ went over Kirkes' ideas on embolisms outside the heart and postulated that, in addition to the consequences resulting from the release of fragments of intracardiac fibrinous vegetations into the blood-stream, fibrinous deposits in the small vessels of organs (in particular the spleen, liver and kidney) could be due to changes in the blood itself.

The numerous microscopic observations Virchow made of the thrombi gradually revealed a vast number of "small granules", smaller than the nucleus of a leucocyte. He found that they were insoluble in potassium hydroxide, acetic acid and nitric acid. But it appears that Virchow paid very little attention to these granules, or at any rate, he did not include them in the theory of cellular pathology or in his ideas on endocarditis. He was to continue in that vein until 1871, when in the fourth edition of Die Cellularpathologie, at the end of the tenth chapter he discussed the role of "these small organisms classified as bacteria, vibrios and micrococci which we have agreed to consider as being vegetal". 50 However, until then Virchow had still not really discussed the role of these bacteria in the endocardium. It should be noted that in 1855 Rokitansky had already detected the presence of "small granulations" resistant to acetic acid in the vegetations on the mitral valve. ${ }^{51}$

\footnotetext{
48 Alfred Hardy and Louis F Béhier, Traité élémentaire de pathologie interne, Paris, 1864, vol. 2, pp. 916-19.

49 Samuel Wilks, 'Select clinical cases', Guy's Hosp. Rep., series 3, 1870, 15: 29-35.
} 


\section{Alain Contrepois}

At that time, it was difficult for doctors to make pronouncements on the nature of the "small granulations" observed in the vegetations. They were unable to determine the function of these microscopic forms and saw no way of relating them to a pathological process. For something to be analysed, it is not enough merely to be aware of its presence; there has to be an accompanying theory. It was only in July 1861 that Pasteur published a Mémoire sur les corpuscules organisés qui existent dans l'atmosphère. ${ }^{52}$ In a study on suppurative endocarditis published in 1862, Lancereaux pointed out that "until now very little is known" about the causes of this disease. ${ }^{53}$ However, he also mentioned the presence of an abundance of "small granulations" in the fibrinous concretions of the heart valves and in the blood observed under the microscope. These granulations, which moved in all directions, were resistant to alkalis and were, according to Lancereaux, foreign elements.

\section{"Parasitic" Disease}

In 1869, the Norwegian Emmanuel Winge (1817-1894) described a very important case to the Medical Society of Christiania (Oslo) which was reported by Gaston Lion. ${ }^{54}$ A completely healthy man removed a corn from the sole of his feet. Five days after it had suppurated, he started to shiver and to sweat heavily; his skin was covered in purpuric spots, his knee joints became very painful, the first heart beat appeared as a "drawling" sound. Within twenty-five days the patient succumbed to the disease. During autopsy, Winge noticed vegetative endocarditis on both sides of the heart, as well as embolisms in the lungs, the left kidney and the spleen. He saw "on the aortic valves grey, felt-like masses, resembling pebbles and which were easily detached". 55 Under the microscope, these thrombus-type masses seemed to be made up of a fine network of fibrinous filament. With greater magnifying power, "these filaments appeared to be entangled with microorganisms which looked like strings of either short, round beads or tiny sticks, somewhat like leptothrix rosaries". These bodies were resistant to both alkalis and acids. Winge willingly admitted that they were "parasitic" organisms which, having entered the bloodstream through a plantar excoriation, were transported to the heart through the veins. He suggested that the affection be called "Mycosis endocardii".

This theory marks an extremely important stage in the understanding of the pathophysiological process of endocarditis. Not only did Winge draw attention to the "parasitic" nature of the disease, but he also suggested that these "parasites", introduced into the organism via the skin, were transported in the blood to the heart where they attached themselves to the endocardium. He therefore accorded a primary pathogenic role to these organisms contained in the tissues taken from the body during autopsy and observed under the microscope. His initiative, which seemed quite novel at the time, also had an experimental side as, after the clinical and patho-anatomical observation was completed, he injected some of the vegetation taken from the dead patient into the skin of

\footnotetext{
52 Claire Salomon-Bayet, Pasteur et la révolution Pastorienne, Paris, Payot, 1986, p. 397.

53 Etienne Lancereaux, 'Recherche pour servir à l'histoire de l'endocardite suppurée et de l'endocardite ulcéreuse', $C$. R. Séanc. Mém. Soc. Biol., 3rd series, vol. 4, 1862, pp. 3-35.
} 


\section{Towards a History of Infective Endocarditis}

a rabbit's back. However, the animal survived after the injection. It is difficult to say precisely how Winge arrived at assigning this pathogenic role to the micro-organisms. The term "leptothrix" leads one to think that the studies of botanists such as Ernst Hallier (1831 - 1904) of Germany might have influenced him. ${ }^{56}$ The "plant-like parasites" are also reminiscent of the work of the Italian Agostino Bassi who spoke of "plant-like microorganisms" and "parasitic mushrooms". 57

Three years later, another Norwegian, Hjalmar Heiberg, reopened the discussion on Winge's observations and himself reported a case of puerperal endocarditis which closely resembled the case cited by Winge. ${ }^{58}$ According to him, the vegetations on the mitral valve and the embolisms of the kidneys and spleen contained uniformly-shaped microorganisms, strung out on a sort of chain. He claimed that the uterine wound acted as an "entrance". Heiberg believed that the parasite in both cases was the leptothrix. However, Virchow, who had studied Heiberg's preparations, added certain comments to Heiberg's article. He claimed that it was wrong to use the term leptothrix because these microorganisms were "vibrions" (he was referring to a classification devised by C G Ehrenberg who included in this term the micro-organisms which would later be known as cocci and bacilli). It should not be forgotten that the observations of Winge, Heiberg and Virchow were made prior to the introduction of staining methods for micro-organisms. Many similar observations were made throughout Europe, particularly in Germany, over the next two years (1874 and 1875). But very often the histological and microscopic tests were carried out only on the corpse and sometimes long after death. Bacteria cultures were not yet being done, injection of animals was rare and, when done, produced very few usable results. However, the techniques of microscopic examination gradually improved.

Shortly afterwards, Edwin Klebs (1834-1913) of Germany expressed his conviction that all cases of endocarditis were of infectious origin, illustrating this with twenty-seven autopsies showing the presence of micro-organisms in the valvular vegetations in each case. ${ }^{59}$ That same year-1878-another German researcher, Karl Koester, postulated that the micrococci entered the vessels the valves were fitted to, thus causing irritation which began in the more internal parts before moving on to the more superficial. ${ }^{60}$ The following year, Joseph Hamburg, a student of Virchow's, discussed the question of how the microorganisms penetrated the valvular vegetations. ${ }^{61}$ His article reflects the extent of the rivalry that still existed between the inflammatory and infectious theories. Moreover, his study represented the first attempt at experimental reproduction of the cardiovascular lesion. Hamburg had two hypotheses: (1) the parasites were transported in the bloodstream and penetrated the vegetations and heart valves mechanically, from the outside to the inside; (2) the vessels on the inside of the valvular tissue were obstructed by embolisms caused by germs. He also mentioned the two theories about how microorganisms entered the blood-stream in the first place: (1) from healthy lungs or intestines;

\footnotetext{
56 William Bulloch, The history of bacteriology, Oxford University Press, 1938, pp. 171-203.

57 Giuseppe Penso, La conquête du monde invisible, Paris, R Dacosta, 1981, p. 279.

58 Hjalmar Heiberg, 'Ein Fall von Endocarditis ulcerosa puerperalis mit Pilzbidunger im Herzen (Mycosis endocardii)', Virchow's Arch. Path. Anat. Physiol., 1872, 55: 407.
}

\footnotetext{
${ }^{59}$ Edwin Klebs, 'Weitere Beiträge zur Enststehungsgeschichte der endocarditis', Arch. Exp. Pathol. Pharmakol., 1878, 9: 52.

${ }^{60}$ Karl Koester, 'Die embolische Endocarditis', Virchow's Arch. Path. Anat. Physiol., 1878, 72: 256.

61 Joseph Hamburg, 'Ueber acute Endocarditis in ihrer Beziehung zur Bacterien', PhD thesis, Berlin, 1879.
} 


\section{Alain Contrepois}

(2) from a point of infection such as a wound.

In order to examine the inflammatory and infectious aspects of the initial valvular lesion, at the request of Virchow, Hamburg undertook an in-depth microscopic study of the vegetations and heart valves based on fourteen endocarditis autopsy cases. ${ }^{62} \mathrm{He}$ detected micrococci in four only. According to him (and no doubt his teacher Virchow shared the same conviction), the other cases were characterized by inflammation to a greater or lesser degree, usually accompanied by underlying tissue destruction. This contradicted Koester's theory, in particular, as he believed that if the valves were exposed over a long period to abnormal mechanical attacks, this would create a favourable terrain for bacteria. However, the bacteria would not pose any problems in these physiological conditions as long as the valves remained intact. Hamburg disagreed. To prove his point, Hamburg induced extensive inflammation in the femoral artery of an animal. This, he said, closely resembled "recent acute endocarditis". As he found no micro-organisms in this experimental "endocarditis" (he probably meant to write "endarteritis"), he was led to believe that acute endocarditis was not necessarily caused by a micrococcus but appeared in a similar manner to parenchymatous inflammations. It was probably the strong influence of Virchow's theory which prevented Hamburg, the student, from going further in trying to find a possible connection between the inflammatory and infectious theories.

Germain Sée (1818-1896), somewhat separated from the others within the French school and an ardent admirer of German methods, was responsible for promoting in France the work that was being done on this disease in Germany. There was no doubt in his mind that "'ulcerative' endocarditis was an acute illness with intense fever, serious general symptoms and all the characteristics of so-called 'infectious' diseases . . . If the cardiac lesion was responsible for most of the morbid manifestations, it was because it was also subject to an infection probably of parasitic origin". Sée, however, posed questions on the pathological process and the terminology used to describe this disease: "Does it really involve an inflammation as the name endocarditis suggests?". The initial lesions would support this interpretation. But from the moment that the presence of microorganisms in the detritus was detected by Winge, Heiberg and others, "we thought we had found the explanation for the alarming rate of inflammation in this disease". Sée believed that, in certain cases, the fibrinous deposits produced an inflammatory reaction before forming outgrowths or vegetations-the reason this type of endocarditis had been qualified as "vegetative". In other cases, there was "necrobiosis" of underlying tissue, which gave rise to the term "ulcerative" endocarditis. 63

For the very first time, Pasteur's name appeared in an article on endocarditis: Sée recognized "M. Pasteur's outstanding work" on anthrax and its parasitic nature. Sée believed that it was the parasitic nature of endocarditis which was responsible for the general symptoms observed: high fever (temperature of $39^{\circ} \mathrm{C}, 40^{\circ}$ and up to $41^{\circ}$ even) and shivering, in particular. The typhic aspect of the disease resulted from "the adulteration of the blood through bacterial infection". Furthermore, Sée believed that when the ecchymotic spots appeared, especially on the limbs, they were of "great pathognomonic

\footnotetext{
62 Saul Jarcho, 'Joseph Hamburg on acute endocarditis and its relation to bacteria (1879)', Am. J. Cardiol., 1973, 31: 509-11.
}

${ }^{63}$ Germain Sée, 'De l'endocardite ulcéreuse', Gaz. méd. Paris, 1879, 31, 33 and 34: 395-7, 418-20, 430-1. 


\section{Towards a History of Infective Endocarditis}

value". The prognosis was all the more serious in the absence of a known case of a cure. He thought that no treatment that had yet been tried (including salicylic acid) had been effective: "If future therapeutics provides us with more effective means of fighting endocarditis, it will certainly come from attacking the root cause, that is, parasitic infection". 64

However, things are never so simple and, shortly afterwards, Michel Peter, in his Traité clinique et pratique des maladies $d u$ coeur, although not questioning the existence of "parasites", expressed reservations and was inclined to believe that these micro-organisms were the result and not the cause of endocarditis. ${ }^{65}$ "The fact that a micro-organism has been detected does not mean that it is efficient; and even if it contributes to the development of the disease, how do we prove that it is sufficient?". ${ }^{6}$ This was the big debate at the time.

All that was known about endocarditis was that the valvular vegetations and the infarctions generally contained micro-organisms. But from the literature of that period, the problem seems to have been posed in the following way: in order to base Winge's hypothesis on a solid foundation, it was necessary to prove that the bacteria had grown in the vegetations on the valves during the patient's lifetime; that they existed in the bloodstream and were not just putrefaction agents. It was also important to find out if the infectious agent was the same in all cases, and if it was a case of a specific affection or secondary disease or of a localization that was common to different morbid species. Although, so far, all attempts had been inconclusive, it was important to try to reproduce endocarditis in experiments on animals so as to provide additional proof in support of the infectious nature of the disease.

\section{IV}

\section{Experimental Reproduction of the Disease}

\section{Necessary and Sufficient Cause}

Pathogenic germs gradually began to be better known thanks to the work of various scientists and doctors across Europe, including Louis Pasteur (1822-1895) and his team in France, and Robert Koch (1843-1910) and others in Germany. ${ }^{67}$ The affirmation of the presence of pathogenic germs in the blood-stream and their culture in an appropriate medium clearly marked the birth of bacteriology. An unprecedented experimental strategy was needed to define properly the micro-organism; not only in terms of its form (description and classification) and physiology, but also in terms of its pathogenic or nonpathogenic function. This complex strategy needed to become a codified laboratory routine so that microbiology could be an "ordinary science". 68

64 Ibid., p. 431.

65 Michel Peter, Traité clinique et pratique des maladies du coeur et de la crosse de l'aorte, Paris, Baillière, 1883, p. 409.

66 Jacques Léonard, 'Comment peut-on être pasteurien?', in C Salomon-Bayet, op. cit., note 52 above, pp. 143-82.

\footnotetext{
${ }^{67}$ William D Foster, A history of medical bacteriology and immunology, London, Heinemann, 1970, pp. 22-63.

68 Salomon-Bayet, op. cit., note 52 above, pp. 46-7.
} 


\section{Alain Contrepois}

It was agreed that an infection could be transmitted through the blood and in 1869 Winge postulated his theory on the transportation of "parasites" from a local cutaneous lesion to the heart. It was important to establish the presence of micro-organisms in the blood because the blood being "the main canal of the body", the centre of distribution, the presence of micro-organisms could lead to diseases being spread to other points away from the original point of affection. Besides, the idea of "cultivating" blood is, of course, closely related to the concept of autonomous, live, pathogenic germs which can therefore multiply and be cultivated. Pasteur stressed the importance of blood tests and blood cultures of animals or living human beings. For him, "a septicaemia is an affection produced by germs which break down the organism's barriers and which are transported by the blood in particular". 69

A long period of much trial and error facilitated the gradual improvement of blood tests and culture techniques in order to prevent contamination and to encourage the multiplication of germs. The first blood tests were carried out on women with puerperal fever, by using a pin to prick the tip of their index finger which was previously washed and wiped with a sterilized cloth. These blood samples allowed Pasteur to obtain pure bacteria cultures. Different culture media were tested: chicken broth, yeast, urine, Liebig's meat broth medium; tests on aerobiosis and anaerobiosis, etc. All this required a considerable practical know-how. "Placing a sterile pipette against the wound and taking a sample of blood, putting a few drops in the urine; these were all new achievements". ${ }^{70}$

However, a prick in the index finger with a needle draws only a few drops of blood, which Pasteur thought was not enough: "It would be quite useful to find a patient who would be willing to receive several pricks in various parts of the body so that we could set up a number of cultures simultaneously or if not, blood from the general circulatory system". This idea of taking blood from different points on the body in order to "track down the germ" indicates not only that Pasteur believed that the germs circulated in the blood $^{71}$ but also illustrates the technical difficulty of getting a sample large enough to facilitate germ culture. In 1880 , blood cultures were systematically done within the hospital context by Jacques Doleris, an obstetrician, on the advice of Pasteur. However, blood sampling was often done posthumously or on dying patients. Doleris noted that the cultures were frequently positive when there was a sudden marked increase in the patient's

\footnotetext{
${ }^{69}$ What was the meaning of the word "septicaemia" in France at that time? Littre and Robin's 1878 Dictionnaire de médecine defines it as an "alteration of the blood which is either a phenomenon of the blood itself or occurs as a result of a wound". However, the 1881 edition of the Dictionnaire encyclopédique des sciences médicales (Raige-Delorme and A Dechambre, 100 vols, 1864-89), points out the influence of the new ideas on infectious pathology: "Although the word 'septicaemia' is derived from the Greek 'septikos', that which produces putrefaction, the meaning has gradually changed. One is less inclined to include putrid infections which only include toxaemia linked to the existence of a decomposition centre where organic matter is slowly putrified. True septicaemia is a purulent infection resulting from the entry and
}

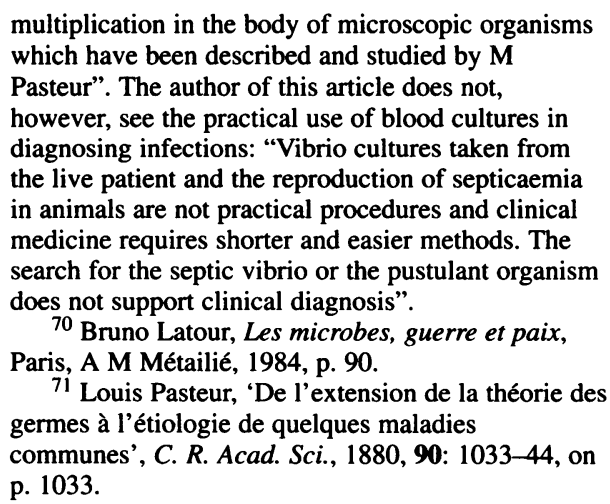




\section{Towards a History of Infective Endocarditis}

temperature or when there was shivering. ${ }^{72}$ Between 1880 and 1885 , as soon as a new bacterial infection was detected, the germ was tracked down in the blood to be matched against one found in another part of the body. So, blood cultures were no longer used for simply verifying a diagnosis. The development of this medical practice evolved as much from new technical and material possibilities as from increased knowledge of human pathology. ${ }^{73}$ However, the technical problems related to bacteriological blood culture were not resolved, in particular the amount of sample taken (a simple prick on the finger could not produce enough blood) and the constant risk of contamination. A marked improvement was brought by the French invention of the piston syringe made from elder's pith and, unlike Pravaz's syringe, easy to sterilize. ${ }^{74}$ In Germany, Sittmann used the syringe designed by Luër with a glass body and asbestos piston. Malassez of France was to design a syringe made completely of glass. ${ }^{75}$ Blood sampling became gradually more standardized over the next few years and what was later to be called "hémoculture", in French, was born-a perfect example of the marriage of a theoretical "revolution" (i.e., the germ theory) and technical innovations. ${ }^{76}$

It was, therefore, no longer a question of observing, under the microscope, samples of lesions detected during autopsy but of trying to discover the micro-organisms responsible for the disease in the "live" patient. This new attitude to the disease gave rise to a new clinical practice, a different kind of interaction with the patient and his body: the patient's body was "inhabited" by microscopic germs which circulated and grew inside it. These had to be tracked down by taking samples of blood, urine, pus, etc., and adding them to the culture media. This meant that there had to be close collaboration between laboratory work and the process of medical diagnosis.

Human endocarditis, blood culture and inoculation of animals were all mentioned in Arnold Netter's work. In 1881, Netter, an intern supervised by Joseph Grancher, submitted to the latter a paper for the 1881 competition entitled 'Recherches sur la nature de l'endocardite ulcéreuse'. Reporting on his student's work, Grancher wrote that Netter

studied organisms in the blood of live patients; he used chicken broth cultures to show that these germs were alive; he injected rabbits and, despite the relative success of his injections, believed that he could prove that the germs were, in fact, the cause of the disease.

Of the sampling of the blood of patients who were clinically proven to have endocarditis, Netter went on to say that he pricked the tip of the index finger which had been washed in alcohol with a sterilised lancet and drew a few drops of blood into a pipette which he immediately sealed with the torch. He observed the germs under the microscope. A blood sample was then incubated in the culture medium in M. Bouchard's laboratory. After

\footnotetext{
72 Jacques Doleris, 'Essai sur la pathogénie et la thérapeutique des accidents infectieux des suites de couches', PhD thesis, No. 236, Paris, 1880, p. 320.

${ }^{73}$ Russell C Maulitz, "Physician versus bacteriologist": the ideology of science in clinical medicine', in The therapeutic revolution: essays in the social history of American Medicine, eds M J Vogel and C E Rosenberg, Philadelphia, University of Pennsylvania Press, 1979, pp. 91-105.

${ }^{74}$ Isidore Straus, 'Présentation d'une seringue à
}

injections pouvant être facilement stérilisée', $C . R$. hebd. Séanc. Soc. Biol., 1886, 38: 37.

${ }^{75} \mathrm{D}$ Malassez, 'Perfectionnements apportés aux seringues tout en verre et stérilisables', $C$. R. hebd. Séanc. Mém. Soc. Biol., 1891, 43: 71-80.

76 Ilana Löwy, 'Medecine and change', in I Löwy (ed.), Medicine and change: historical and sociological studies of medical innovation, Paris, INSERM, 1993, pp. 1-20. 


\section{Alain Contrepois}

forty-eight hours, there were "some magnificent rosary-like chains". Netter's conclusion seemed to be based on the diversity of types of microbes observed: "endocarditis is an anatomical and clinical symptom which can appear during various infections."

The germ theory, therefore, played a vital role in rendering micro-organisms of living particles useful for the study of the disease. After making this "choice", which was more of a "gamble" than anything else, doctors could turn to such questions as causality, research and treatment of causes. The disease was seen as a relatively coherent whole where the symptoms were related to etiology and that opened the era of the experimental reproduction of diseases in laboratories. The germ theory only temporarily supported the idea of a specific medical cause. This could not really be applied to endocarditis in which, over time, several types of micro-organisms were found to exist in the lesions or in the blood. This fact was of extreme importance because it contradicted the idea that one single micro-organism had to correspond to one disease. But this did not apply only to endocarditis; similar observations were made for pneumonia, pleurisy, angina, etc. Hence the reason for the term "infectious" endocarditis employed by Grancher in 1884.

Subsequently, Grancher himself made a clinical observation (1884):

Len. Marc, 32-years-old, was admitted at the Necker Hospital on July 21, 1883 . . In April 1882, the patient had been afflicted with generalized acute rheumatoid arthritis with cardiac complications. At the beginning of May 1883, he had a violent attack of oppression with cardiac palpitations ... During the months of June and July, the inappetence, fatigue, palpitations and pallor increased, which led the patient to enter hospital. He was in a marked state of prostration, his face was pale and thin. The inappetence and weakness continued along with the palpitations coupled with precordial malaise and insomnia. Temperature: $39^{\circ} 8 \mathrm{C}$ in the evening; $38^{\circ} 5$ in the morning . . We heard a diastolic murmur at the base of the heart. Diagnosis: over-stress, aortic insufficiency. On July 25 , hemiplegic paralysis ... The dyspnoea became so intense and the precordial oppression so great that we were led to think that it might be ulcerative endocarditis . . Prostration steadily continued up to August 10 accompanied by delirium at night, high fever (temperature fluctuating around $39^{\circ}$ ), shivering and finally oedema in the lower limbs. On August 1, 3, 5, 6, 7, 8 and 9, I daily cultured a drop of the patient's blood, "sterilely taken", in $20 \mathrm{~g}$ of Pasteur medium. After 24 hours, each of these cultures produced small, whitish, round grains ... The blood examined under the microscope contained micrococci which appeared either singly or in pairs. The patient died on August 10. During the autopsy, I took a "pure" sample of blood from the left auricle and ventricle to be cultured (I obtained the same micro-organism as when the patient was alive). The autopsy verified the diagnosis: ulcerative endocarditis due to the aortic valves' appearance as dropsical swellings covered by rough, granular, soft vegetation ... An examination under the microscope revealed an infinite number of minute but very uniform micrococci, scattered over the surface of the vegetations ... When the grains from the culture medium were compared with those on the vegetations, they were discovered to be of the same organism, which were coloured with gentian blue.... There is no doubt, therefore, that while Len. was alive, his blood contained micrococci which could grow and live in contact with oxygen. . . . We had yet to determine the pathogenic role of these bacteria in Len.'s illness. Was this disease, which should be called infective endocarditis rather than ulcerative endocarditis as there was no visible ulceration on the endocardium, due to aerobic bacteria found in the blood, was the bacteria an accessory or concomitant element? In order to solve this problem, the disease would have to be reproduced in inoculated animals. ${ }^{77}$

77 Joseph Grancher, 'Le microcoque de l'endocardite infectieuse', Bull. Mém. Soc. méd. Hôpitaux de Paris, 1884, 3rd series, 1: 213-22. 


\section{Towards a History of Infective Endocarditis}

In order to prove that the germ was the cause of "infectious" endocarditis, it was therefore deemed necessary to reproduce the infection in an animal. The quoted references indicate that Grancher was not only familiar with the work of Pasteur, as would be expected, but also with that of German researchers, in particular Klebs. The idea of there being a cause which was necessary to the development of certain infectious diseases ${ }^{78}$ became popular between 1860 and 1870 thanks to Carl Mayrhofer, Jacob Henle and Edwin Klebs in particular, and later Pasteur and Koch. ${ }^{79}$ In an article published in 1876 on ammoniacal urine, Pasteur outlined a strategy to show the need to identify a cause: isolation of the micro-organism, obtention of a pure culture and re-inoculation into a different organism. However, the use of liquid media made it difficult for Pasteur to isolate pure cultures, whereas Koch used solid gelose media. Koch stated his famous "postulates" in his 1882 publications on tuberculosis and anthrax. ${ }^{80}$

Animal experimentation assumed that there were phenomena which were common to both humans and animals. ${ }^{81}$ It also presupposed that the live being was available for experimentation and the increase of knowledge. However, endocarditis is not a disease which can be transmitted from one person to the next and the question of the point of entry remained unsolved. As for animals used in laboratory experiments, the injection of pathogenic bacteria did not seem to be sufficient to reproduce the valvular lesions of the disease.

\section{Experimental Endocarditis}

In 1878, Ottomar Rosenbach (1851-1907) of Breslau, and a student of Julius Cohnheim, examined the possibility of reproducing endocarditis in animals as well as the likely after-effects. ${ }^{82}$ In the introduction to his article, Rosenbach cited Magendie for experimental physiology and Bouillaud for his work on endocarditis. Rosenbach's work was inspired by techniques developed by Otto Becker, Cohnheim and, in particular, Edwin Klebs' study of the surgical wounds of the heart valves and their after-effects. ${ }^{83}$ Klebs, who would admit to the infectious nature of endocarditis two years later, had developed experimental surgical techniques with the main objective of studying the circulatory consequences of valvular insufficiency. However, it was Rosenbach, not Klebs, who would combine experimental physiology with experimental infection thereby establishing the first endocarditis animal model. ${ }^{84}$

He mechanically induced an injury in a rabbit's aortic valves by pushing a stylet into the carotid artery straight through to the left ventricle. When the instrument was aseptic, at autopsy the perforation was either still visible or healed but there was no trace of

\footnotetext{
${ }^{78}$ A S Evans, 'Causation and disease: the HenleKoch postulates revisited', Yale J. Biol. Med., 1976, 49: 175-95.

${ }^{79} \mathrm{~K}$ Codell Carter, 'Koch's postulates in relation to the work of Jacob Henle and Edwin Klebs', Med. Hist., 1985, 29: 353-74.

80 Ibid., pp. 357-9.

81 W F Bynum, "“C'est un malade": animal models and concepts of human disease', J. Hist. Med. allied Sc., 1990, 45: 397-413.
}

\footnotetext{
82 Ottomar Rosenbach, 'Ueber artificielle Herzklappenfehler', Arch. exp. Pathol. Pharmak., 1878, 9: 1-30.

${ }^{83}$ Edwin Klebs, 'Ueber operative Verletzungen der Herzklappen und deren Folgen', Prager med. Wochenschr., 1876, 1: 29-36. See also, H Ebert, 'Mycotische Endocarditis'; Arch Path Anat., 1878, 72: 103.

84 Saul Jarcho, 'Artificial insufficiency of heart valves (Rosenbach, 1878)', Am. J. Cardiol., 1967, 19: $850-3$.
} 


\section{Alain Contrepois}

infective endocarditis. However, when the instrument was covered with septic matter, vegetations and fibrinous deposits, which in turn produced septic embolisms, were formed around the wound.

Experimental endocarditis, therefore, resulted from the combination of the model elaborated by Klebs, himself inspired by the "Bernardian" animal model of experimental physiology, ${ }^{85}$ and the "infectious" animal model which was injected with a microorganism in order to observe how an infectious disease was transmitted. Separately, the methods were ineffective but together they produced efficient results. Indeed, the injection of pathogenic germs into the blood was not sufficient to produce the disease. Only certain bacteria seemed able to be grafted onto the valves. The valves, for their part, had to be damaged, just slightly, for the bacterial graft to be possible. Damage to the valves alone was not enough to induce infective endocarditis.

Rosenbach's experiments were repeated by Johannes Orth, ${ }^{86}$ then by Vladimir Wyssokowitsch (1854-1912). The latter, of the University of Kharkov, went to Göttingen to study pathology under Orth's supervision. ${ }^{87}$ In their experimental model, once the valvular lesion was produced following Rosenbach's technique, they injected cultures of specific bacteria into the vein of a rabbit's ear (following Winge's theory). They concluded that after inducing the preliminary lesion in the heart valves, it was possible to produce infective endocarditis by introducing different species of bacteria into the blood-stream. They pointed out, however, that without the preliminary lesion on the valves, the results were negative. ${ }^{88}$ Orth went so far as to admit that, in humans, infective endocarditis was always "grafted" onto a previous lesion on the valves.

That same year, 1886, in France, Netter studied "pneumonic" endocarditis. ${ }^{89}$ The incriminated germ was tracked from the pulmonary lesion, the point of entry, to the blood, while the patient was alive, and to the valvular lesions after death. The diplococcus of Talamon and Fraenkel, of which the pathogenic effect on animals is well known, was found in the endocarditic vegetations of the patient. Bacterial cultures from "pneumonic juice" samples, blood samples and vegetations revealed the presence of the same germ. After inoculation of the rabbit, pure cultures facilitated the production of a "general infection", pleuro-pneumonia, or endocarditis occurring after the preliminary lesion of the valves. In this last case, Netter induced traumatism in the rabbit's heart following Rosenbach's method.

In discussing the mechanism of the infection, Netter pointed out that during the course of some types of pneumonia,

the germs may enter the blood and then be deposited in different organs and, if the conditions are favourable, will develop in a new way possibly leading to endocarditis. There are two types of

\footnotetext{
85 John Lesch, Science and medicine in France: the emergence of experimental physiology, 1790-1855, Cambridge, Mass., Harvard University Press, 1984, pp. 1-11; see also, W R Albury, 'Experiment and explanation in the physiology of Bichat and Magendie', Stud. Hist. Biol., 1977, 1: 47-131.

86 Johannes Orth, 'Ueber Untersuchungen betrefls der Aetiologie der akuten Endocarditis', Wien. med. Wochenschr., 1885, 35: 1218.
}

\footnotetext{
${ }^{87}$ Saul Jarcho, 'Experimental endocarditis (Wyssokowitsch, 1886)', Am. J. Cardiol., 1969, 24 : 876-9.

${ }^{88}$ Vladimir Wyssokowitsch, 'Beiträge zur Lehre von der Endocarditis', Arch. Pathol. Anat. Phys., 1886, 103: 301-32.

89 Arnold Netter, 'De l'endocardite végétante d'origine pneumonique', Arch. Physiol., 1886, pp. 106-61.
} 


\section{Towards a History of Infective Endocarditis}

causes in the aetiology of this disease: those which facilitate the spread of germs and those which cause the germs to become embedded into the endocardium. The second case is easy to imagine. All we need to do is to think back to our recent experiments in which we were able to produce endocarditis whenever we damaged the inner membrane of the heart. ${ }^{90}$

Work was also conducted in Austria. Anton Weichselbaum (1845-1930) was professor of Histopathology and Bacteriology at the University of Vienna. Bacteriology was, therefore, an emerging science officially recognized even then at that university. Two years before isolating the meningococcus, he published a study on the aetiology of acute endocarditis. ${ }^{91}$ After citing Orth's work, he recalled the distinction made between acute and chronic endocarditis which were further divided into an ulcerative (diphtherial) form and a vegetative (rheumatic) form. He pointed out that, for many researchers, the aetiology of these different forms was due to micro-organisms and he referred to the research carried out by Klebs and Koester, in particular. ${ }^{92}$ Noting that the results of tests were not always clear in the case of acute endocarditis, he suggested that both clinical and experimental cases be used. In the cases reported, often preceded by acute rheumatoid arthritis, Weichselbaum prepared no blood culture while the patients were alive, unlike his French counterparts, but took samples of vegetation and of organs at autopsy, then put these in cultures. The sampling technique improved; he used Pravaz's syringe and the agar-agar dishes. He found bacteria in all cases, in particular Streptococcus pyogenes and Staphylococcus aureus. Experimental endocarditis was carried out on rabbits using Rosenbach's technique. The following day, they were injected intravenously (as Wyssokowitsch had done) with bacteria from the cultures of the samples taken at autopsy. Weichselbaum also concluded that, in order to produce experimental endocarditis, it was necessary to have a previous valvular lesion, as the injection of bacteria without prior traumatism was not enough to induce the disease. When he examined the vegetations under the microscope, he saw the cocci close to the surface and therefore concluded that the micro-organisms reached the valves through the blood circulating in the heart cavity and not via the small blood vessels inside the valves as Koester had proposed. Furthermore, after conducting several tests, he concluded that only certain types of bacteria were likely to adhere to the valves, notably the streptococcus and the staphylococcus. He questioned the negative results of the search for bacteria in the vegetations of certain types of endocarditis and believed that it was difficult to give a precise explanation as the germ could have died before or during the cultures.

\footnotetext{
90 Ibid., pp. 120-3: "We identified the carotid artery which runs through the trachea; we isolated the vessel and attached two threads. The upper thread was knotted straightaway. The lower was only tied once the probe was removed. The vessel was gripped with the forceps and an incision made between the forceps and the upper thread; then the probe was introduced and pushed down the vessel. After 9 to 10 centimetres, there was some resistance where the tip of the probe became lodged in a sigmoid valve; with some amount of force, the instrument penetrated the ventricle. Success of the operation was marked by exaggerated beating of the arteries ... we used the stylet probe adopted by Rosenbach and Wyssokowitsch ... Once the heart was prepared, the
}

wound was dressed as antiseptically as possible. The lips were sutured. The animal did not seem very uncomfortable. The day of the operation, or the following day, liquid filled with pneumococci was injected into the animal". Netter added that, "in terms of the experimental technique, the cardiac traumatism did not need to be great; slight palpation was sufficient."

91 Anton Weichselbaum, 'Zur Aetiologie der akuten Endokarditis', Wien. med. Wochenschr., 1885, 35: $1241-6$.

92 Saul Jarcho, 'Anton Weichselbaum on the etiology of acute endocarditis, 1885', Am. J. Cardiol., 1973, 31: 774-7. 


\section{Alain Contrepois}

The tests carried out on the experimental endocarditis animal model helped significantly to deepen the understanding of the pathophysiological mechanism of the disease subsequent to Winge's theory formulated in 1869.

\section{Complex Disease}

The idea that the same germ did not always provoke the same disease was reiterated by Émile Duclaux during the lectures he gave at the Sorbonne between 1885 and $1886 .^{93}$ Similarly, different types of bacteria could produce the same disease. This departed somewhat from the first idea of the existence of a specific germ. Unlike tuberculosis, typhoid, syphilis, the plague, cholera, etc., certain infectious diseases could be caused by a number of different bacteria. This was first recognized in the case of pneumonia, pleurisy, meningitis, angina, septicaemia and endocarditis. This, then, was the reason for bacteriological diagnoses based on samples taken from the bodies of patients. Research on blood cultures continued alongside clinical and experimental work. The development of these techniques, often forgotten in the face of clinical advances, was very important. In the case of endocarditis and the process leading up to the illness, blood culture was essential from a diagnostic point of view. A von Eiselsberg, a Viennese researcher who studied the presence of germs in the blood between 1886 and 1890, was convinced that blood culture was an effective diagnostic tool. ${ }^{94}$

However, the fact that there could be several causative bacteria posed problems for a number of doctors. The cause of preliminary valvular lesion was again the subject of discussion. Was this caused by a germ? Was the germ specific? Doctors hesitated and shifted from one position to another; the causes seemed complex and intertwining; speculations were constantly being revised and no idea fully led to another. For Lion, infective endocarditis, "first of all, a local disease subsequently generalized by the mixture of vegetative matter with the blood, must be seen as an affection preceded by the introduction of a germ into the blood-stream and thus must be considered a general affection". The "terrain" and resistance to the illness were of foremost importance. The question of the point of entry of the germs was not entirely clear, but Lion believed that simple angina or a slight case of bronchitis could create this entry point. ${ }^{95}$ Meanwhile, for most doctors, blood culture became an essential biological examination for diagnosis.

In practice, medicine was to see the mirage of a single cause disappear as it was approached. Thus, in infective endocarditis, proof of the presence of a bacterial agent in the blood was not a strong enough basis for a diagnosis. Nevertheless, when coupled with other signs and symptoms such as fever, heart murmur, enlarged spleen and certain peripheral lesions, blood culture aided diagnosis considerably. It would be some time before this had consequences for therapy. It was necessary also to take into account the virulence of the germ, its ability to lodge itself onto the endocardium, the "terrain" of the patient, and especially the latter's medical history as the disease resulted from the interplay of all these different factors. Previous heart attacks which were congenital or due to acute rheumatoid arthritis certainly seemed to be important.

\footnotetext{
93 Emile Duclaux, Le microbe et la maladie, Paris, Masson, 1886, p. 137.

${ }_{94}$ A von Eiselsberg, 'Nachweis von Eitercoccen
} 


\section{Towards a History of Infective Endocarditis}

At the same time, the contribution of bacteriology and experimental medicine made it even harder to understand this disease. Consequently, classification of endocarditis based on different clinical forms seemed difficult at the outset. It was in the United States that well documented studies would be conducted on a large number of patients. Extensive clinical monographs were subsequently published.

\section{$\mathbf{V}$}

\section{Attempts at Classification}

It would be fifteen to twenty years before a classification of endocarditis was established which would temporarily gather together all the knowledge that had so far been accumulated on the disease. The attempts at classification resulted from a clinical rethinking of the affection in different forms as well as from improved knowledge of bacterial aetiology. Different clinical forms were then related to different germs. It was through combining the clinical and the bacteriological approaches that some sort of typology was established. The clinical classification was, more or less, modified by the bacteriological diagnosis through mutual construction.

\section{"Acute" and "chronic" Endocarditis}

One of the great endocarditis clinicians at the turn of the twentieth century, William Osler (1849-1919) of the United States would lend his name to this disease; today we speak of "Osler's endocarditis" and "Osler's nodules". Yet Osler did not formulate any particularly original theory or make any important discovery. It was his ability for clinical synthesis which was outstanding. As early as 1881 , at a medical conference in Europe, he expressed his views on endocarditis and supported the ideas of Klebs. ${ }^{96} \mathrm{He}$ made reference to the "spherical bodies" resembling micrococci, but these elements did not explain the seriousness of the affection. He thought that the reason for the gravity of the disease lay in the possible "debility" of the subjects.

A few years later, he gave a lecture on "malignant" endocarditis. The term is significant and indicates the seriousness of the disease and the highly negative prognosis attached to it. Osler briefly went over the work which had already been done, recalling Kirkes, Charcot, Vulpian, Lancereaux and Virchow but without mentioning Bouillaud, Winge, Netter or Grancher. He situated his work in a period where the relationship between endocarditis and often associated diseases needed to be determined. That is, he tried to dissociate endocarditis from a set of affections. He immediately pointed out the difficulty of nomenclature and classification and suggested that the term "acute" be used for forms characterized by vegetations and exudation on the surface of the endocardium with the possibility of continuity or loss of substance, and the term "chronic" for cases where there was slow sclerosed transformation ending in thickening, folding and deformation but no vegetations. According to Osler, acute endocarditis was produced accidentally during

\footnotetext{
96 William Osler, 'On some points in the etiology and pathology of ulcerative endocarditis', Trans. int. med. Cong., 1881, 7th session, vol. 1, pp. 341-6.
} 


\section{Alain Contrepois}

various infectious processes. However, complications arose very quickly. He made a distinction between "simple" endocarditis and the "ulcerative, infectious malignant" type. The latter could be "primitive", or "secondary" to acute rheumatoid arthritis, pneumonia or various infectious fevers. He complicated things even further by mentioning two other types of malignant endocarditis, namely the "septic" or "pyemic" type, similar to extreme septicaemia, and the more frequent "typhoid" type with less irregular temperature and early prostration.

The description of the endocarditic vegetation was, however, very precise:

It is made up of cells derived from the subendothelial layer . . . which by their proliferation have produced a small nodular projection on the surface of the endocardium. . . What part the endothelium plays in this growth has not been determined. . . there is deposited upon it a cap of fibrine in the form of a granular, sometimes stratified, material, of variable thickness. Though this resembles an ordinary coagulable exudation, it is probably deposited directly from the blood, and is of the nature of a thrombus. Upon and in this layer may be found, sometimes in large numbers, those remarkable little bodies . . . which have of late become so prominent as the blood-plates [sic] of Bizzozero, ... the connexion of which with fibrine formation has been so strongly insisted upon by [this author]. ${ }^{97}$

This was the first time that mention was made of the blood platelets associated with fibrin in the vegetations and Osler confirmed the generally held opinion of the time that these elements had their origin in the blood-stream and were not a secretion from the endocarditic lesion. Osler added that there were numerous little granular bodies in the fibrinous network which looked like micrococci. According to him, these microorganisms were best observed under the microscope after coloration with "Gramm" (which he spelt with two " $\mathrm{m}$ 's") and the germs detected were not always of the same type.

Osler outlined the major features of the "slow" type of endocarditis: previous valvular lesion linked to acute rheumatoid arthritis or congenital valvular abnormality; irregular and intermittent fever which, according to him, was a major symptom; sweating; heart "murmur"; embolisms arising later; embolic process giving rise to certain manifestations on the skin which often helped to replace uncertainty with a definite diagnosis or to correct a clinical impression that was "off track". He admitted that these signs and symptoms, except perhaps for the irregular and intermittent fever, had been described previously. He claimed that the illness could be prolonged for three or four months. Osler then addressed the question of diagnostic and aetiological difficulties more precisely but without mentioning the blood culture: "Few diseases present greater difficulties in the way of diagnosis than malignant endocarditis, difficulties which in many cases are practically insurmountable". He then returned to rheumatism in the aetiology of endocarditis and cited Bouillaud. He went on to discuss the progression of the disease where the local and general effects were linked to the growth of bacteria on the heart valves and the transportation of these bacteria away from the original point of affection. In conclusion, Osler made a superb presentation of the "outlines of our ignorance" 98 and enumerated three points:

\footnotetext{
97 William Osler, 'Malignant endocarditis', Gulstonian Lectures, 1885, Lancet, i: 415-18, on p. 416.
}

\footnotetext{
${ }^{98}$ Raymond D Pruitt, 'William Osler and his Gulstonian lectures on malignant endocarditis', Mayo Clin. Proc., 1982, 57: 4-9.
} 


\section{Towards a History of Infective Endocarditis}

In the first place, we do not yet know, with sufficient accuracy, the frequency of the occurrence of microbes in simple endocarditis ... Secondly, we want full information of the various forms of micro-organisms occurring in secondary endocarditis, and of their relation to the microbes assumed to be the cause of the primary disease. And, thirdly, we are only at the threshold of inquiries relating to the culture of these organisms, to the macroscopic characters of their growth, and to the possible experimental production of endocarditis.

Osler showed his remarkable talent for clinical synthesis at these 1885 conferences but did not seem to be very familiar with the practical bacteriological expertise which had already been developed in France. He made no reference to the diagnostic importance of blood culture or the work of Doleris, Netter and Grancher on this topic. He was also very general and vague when, at the end of his conclusion, he mentioned the possibility of reproducing experimental endocarditis.

Meanwhile, Sigismond Jaccoud was supplying additional information in France on "slow" endocarditis, the insidiousness of the preliminary manifestations as well as their successive stages of development. ${ }^{99}$ The term "infective endocarditis" proposed by Grancher in 1884 seemed to have been adopted by some French doctors. ${ }^{100}$ The importance of the "slow" forms was gradually confirmed.

In 1899, in Vienna, Hermann Lenhartz described types of endocarditis caused by staphylococci, streptococci, pneumococci and gonococci. ${ }^{101} \mathrm{He}$ believed that the acute streptococcus type occurred in patients with general alteration, high and irregular temperature and shivering, and was usually due to the "ordinary" streptococcus. On the other hand, in the chronic type, the attack was gradual and the disease advanced more slowly; there were usually petechias, infarctions of the spleen and of the kidneys and at times cerebral complications such as aphasia and paralysis. The micro-organism detected in the blood cultures of these patients was not the "ordinary" streptococcus, but a "delicate" or "little" streptococcus characterized by slower growth and the absence of virulence in the case of animals. This comparative description of the acute and chronic forms of streptococcic endocarditis was clear and it would be interesting to compare it to Osler's description.

In Munich, Hugo Schottmüller insisted on one bacteriological fact: when the "ordinary" streptococcus was allowed to grow on blood agar, it provoked haemolysis whereas the "little" streptococcus described by Lenhartz produced a greenish pigment as it grew. It is for this reason that he named the latter Streptococcus mitior seu viridans. He underlined the importance of this germ in the aetiology of chronic endocarditis and highlighted a particular clinical entity which he called "endocarditis lenta" (slow endocarditis). ${ }^{102}$

Nearly thirty years after the first studies conducted by Doleris and Netter in Paris, Osler finally noted the importance that blood culture ${ }^{103}$ could have for diagnosis: "With carefully made blood-culture, one should now be able to determine the presence of the

\footnotetext{
${ }^{99}$ Sigismond Jaccoud, Cliniques de la pitié, 24/11/1885, 6 et 9/2/1886.

100 Henri Godonnèche, 'Contribution à l'étude des endocardites infectieuses', $\mathrm{PhD}$ thesis, Paris,

No. 249, 1897, pp. 13-16.

${ }^{101}$ Major, op. cit., note 45 above, p. 357.

102 H Schottmüller, 'Endocarditis lenta', Münch. med. Wochenschr., 1903, 20 : 849.
}

103 The relationship between the clinic and the
laboratory, especially in the area of infectious
diseases became closer and closer. Many small
bacteriological laboratories were set up in medical
services, closer to the patients. The constantly
developed and improved bacteriological techniques
became an ever more precise diagnostic tool for
clinicians. This was particularly true for blood tests




\section{Alain Contrepois}

septicaemia". ${ }^{104}$ His practical application of it seemed to be very recent as he mentioned having used it for diagnosis on only the three newest patients in his series. Besides, it was positive in only one case. Osler also pointed out that he had done vegetation cultures in six out of ten cases; they were negative in three, the streptococcus was present in two, and the staphylococcus in another. There therefore seemed to be a time-lag between his work and that of the "Pasteurian" clinicians who had long been combining clinical examination and bacteriological savoir-faire in the laboratory.

\section{"Acute" and "subacute" Endocarditis}

Shortly after Osler's work on chronic endocarditis, another study was published in the United States-that of Emanuel Libman (1872-1946), a great specialist on the disease in New York. Forty-three cases of "subacute" endocarditis were reported and several microorganisms isolated. The authors contrasted acute endocarditis, which was fatal within a matter of days, with subacute endocarditis which could last from five to six weeks to a year-and-a-half. From that point onwards, those two terms facilitated classification of infective endocarditis in English-speaking countries. According to Libman and Celler, in the case of subacute endocarditis there was always fever, sometimes low, other times high and intermittent, with or without shivering. Once the disease had set in, there was regular sweating. The patient got weaker and weaker and the spleen was generally palpable. ${ }^{105}$ "Osler's cutaneous nodules" (Kirkes had already described them in 1852) were pathognomonic. It was Osler's name which would be given to the "subacute" form of endocarditis, although it was Libman who proposed the term. Libman spoke of "Osler's cutaneous nodules" whilst Osler referred to the "'nodosités cutanées éphémères' of the French" in his article written in $1909 .{ }^{106}$ The mystery of names . . .

Blood cultures were done in thirty-six cases while the subjects were still alive. With respect to these, Libman wrote: "It is noteworthy that in a few cases it was necessary to make several cultures before a positive result was obtained". The question of bacteriological diagnosis then became a veritable leitmotif. The germ found in thirty-five cases was a small "atypical" non-haemolytic streptococcus which grew very slowly and was not very pathogenic in mice. The authors referred to it as the "attenuated streptococci of endocarditis". ${ }^{107}$ However, Libman and Celler disagreed with Schottmüller that only this micro-organism was specific to subacute endocarditis. In fact, they found an influenza bacillus in one case and cited other cases where another germ had been found. In

and cultures which were beginning to be standardized. See M Nicolle and P Remlinger, Traité de technique microbiologique, Paris, Doin, 1902, p. 265: "On the one hand, it is necessary to use a certain amount of blood and on the other hand, every effort must be made to avoid contamination of the skin by microbes. The best thing to do is to take blood directly from a vein ... After sterilization of the elbow, that is, soaping and then washing with alcohol or ether, a ligature is done on the mid-arm. The sterilised needle of the syringe is then carefully introduced into the vein ... The blood taken is then immediately cultured". Blood culture, which is done to ascertain the presence of microbes in the patient's blood, became more and more important in France and Germany especially (see A Lemierre,

'L'ensemencement du sang pendant la vie; procédé d'investigation clinique', PhD thesis, Paris, No. 532, 1904, pp. 5-10).

104 William Osler, 'Chronic infectious endocarditis', Q. J. Med., 1908-9, 2: 219-30.

${ }^{105}$ Emanuel Libman, and L Celler, 'The etiology of subacute endocarditis', Am. J. med. Sci., 1910, 140: 516-27.

106 Osler, op. cit., note 104 above, p. 222.

${ }^{107}$ Libman and Celler, op. cit., note 105 above. 


\section{Towards a History of Infective Endocarditis}

conclusion, they stated that they had made 2,750 blood cultures since 1902 and had found several types of germs in acute endocarditis (streptococci, staphylococci, pneumococci, etc.). According to them: "The absolute diagnosis must, for the present, rest on the cultural study of the blood". 108

By way of conclusion, the history of the illness of Gustav Mahler (1860-1911) gives a clear picture of all the medical knowledge that existed on endocarditis at the beginning of the twentieth century as well as the diagnostic methods and treatment advised. In 1907, a "compensated mitral contraction" was diagnosed in Vienna. ${ }^{109}$ In February 1911, then in New York, Gustav Mahler developed a sore throat. The following day, fever with sore throat and angina were diagnosed. He seemed better for a few days but then the fever returned, first very slightly, before becoming more intense and oscillating. This time the patient was immobilized. At the beginning of March, his doctor, fearing endocarditis, consulted Emanuel Libman. According to Dr Baehr, Libman's young associate at the time:

Libman clinically confirmed the diagnosis of a chronic mitral disease; having detected the characteristic systolic-presystolic murmur in the precordium, prolonged mild fever, palpable spleen and petechias. In order to confirm the diagnosis bacteriologically, Libman asked me to join him at the patient's bedside, at his hospital with the necessary instruments and material for a bacterial culture. Upon arrival, I took $200 \mathrm{cc}$ of blood from a vein in the arm using a syringe and a needle. I poured some of this amount into several test tubes and mixed the rest with a medium of melted agaragar which I then poured into sterile petri dishes. After four to five days of incubation at the hospital laboratory, the dishes were seen to contain numerous bacteria colonies and all the test tubes had a culture of the same microbes which were identified as streptococcus viridans. ${ }^{110}$

A second blood test was done by a doctor at the Rockefeller Institute where serum had begun to be prepared from the patient's blood. On 8 April Mahler set out for France and arrived a week later. The French specialists contacted from New York were not in Paris (it was Easter). André Chantemesse (1851-1919), of the Pasteur Institute, agreed to cut short his vacation and immediately placed the patient in the clinic. On 20 April he decided to continue the serum treatment. Chantemesse was optimistic that the treatment would work as long as the heart resisted. He especially prescribed Metchnikoff's Bulgarian milk ... On 25 April the fever subsided and the patient generally improved. On 30th, Chantemesse made a new blood culture and at the beginning of May he noticed that the streptococci were still growing. However, Chantemesse continued to hope that his serum would manage to kill the germs. Nevertheless, the disease progressed. On 9 May Mahler had pains around the heart and several attacks of suffocation. Chantemesse noticed that the streptococci were present in

\footnotetext{
108 Bacteriological blood culture became an essential tool. The term "hémoculture" (in French) was apparently used for the first time in France, in 1911 , in the second edition of G Roux and A Rochaix's Précis de microbie et de technique bactérioscopique, Paris, Maloine, 1911, p. 570: "When using a culture to test for the presence of microbes in the blood ...., it is absolutely necessary to draw the blood directly from the vessels and never use blood taken from a simple prick of the finger. Blood cultures were not done according to ordinary rules: we found ourselves grappling with unusual
}

\author{
technical difficulties due to the small number of \\ microbes in human blood during septicaemia as well \\ as the bactericidal properties of the serum ...". Then \\ followed a very precise description of the technique \\ of blood sampling and culture. At that time, iodine \\ tincture replaced mixtures previously used for \\ disinfecting the skin. \\ ${ }^{109}$ H L De la Grange, Gustav Mahler, 3 vols, \\ Paris, Fayard, 1984, vol. 3, pp. 957-92. \\ ${ }^{110}$ N B Christy, B G Wood, 'Gustav Mahler and \\ his illness', Trans. Am. Clim. Ass., 1970, 82: 200.
}




\section{Alain Contrepois}

various parts of the body and that there was a swelling just above the knee. To counteract that, he decided to apply sulphate and radium powder. The patient had to be injected with morphine. Another doctor, Professor Chvostek of Trieste, told Mahler that he could help him on condition that he took him to Vienna. However, at the same time, he told Alma Mahler that there was little hope left for her husband. The musician died in Vienna on 18 May 1911 at the age of fifty-one. The Tenth Symphony was never completed.

\section{Conclusion}

Through this historical study of infective endocarditis, I have attempted to demonstrate the evolution of medical knowledge: a blend of theory and practice. ${ }^{111}$ What Bouillaud described as "endocarditis" in 1835 was redefined and "reframed" by each new generation. ${ }^{112}$ This illustrates the restricting force of successive theories and how faith was placed in each one, in its turn. Although a bacterial cause seemed to have been identified, the problem of the cause of primitive lesions on the endocardium and the question of "terrain" remained unsolved.

Identification of the multiple causative factors ${ }^{113}$ which are necessary for understanding the disease, was sometimes jeopardized by the succession of mutually exclusive theories. Doctors relied on different combinations of criteria, first clinical, then biological, so complex was the disease and its causes. The clinician's logic looks at combinations and chooses the criteria to be associated in order to construct a plausible scheme of causes. For example, the collected data pointed towards acute and chronic endocarditis as two separate entities caused by two different strains of bacteria. But this view would later be challenged when other bacteria manifested themselves. Each time, these changing positions, hesitations and "mistakes" added further to the accumulated knowledge. Canguilhem maintained that medicine, like any other discipline, is built as much from errors as from truths; errors which play a positive role often inseparable from that played by truth. ${ }^{114}$

Lastly, we have seen the concept of infective endocarditis reshaped over a century. Different aspects of the disease were replaced and redefined according to the preoccupations and tools which were specific to each period. However, some of Bouillaud's questions and original theories are still relevant today, which should make us re-evaluate the impact of the bacteriological revolution which has often been linked to the emergence of modern medicine. Bacteriological science proposed new etiological categories but, above all, it introduced new practical techniques.

The description of infective endocarditis has brought the old spectre of infections of the pre-Pasteurian era into the present era of therapeutic optimism (antibiotics). The disease unites archaism and modernity through the problems it expects bacteriology to resolve and the sophistication it brings to microbiological techniques which have been tried and proven in other diseases.

\footnotetext{
111 Christiane Sinding, Le clinicien et le chercheur, Paris, PUF, 1991, p. 237.

${ }^{112}$ Charles E Rosenberg and Janet Golden, Framing disease: studies in cultural history, Brunswick, Rutgers University Press, 1992.

113 Anne-Marie Moulin, 'The dilemma of medical
}

causality and the issue of biological individuality', in C Delkeskamp-Hayes and M A Gardell Cutter (eds), Science, technology and the art of medicine, Dordrecht and Boston, Kluwer, 1993, pp. 153-62.

114 Georges Canguilhem, La connaissance de la vie, Paris, J Vrin, 1989, p. 31. 